\title{
Construction of Teaching Assisted Expert System in Engineering Training
}

\author{
ZHANG Zhi-gang ${ }^{1}$ \\ Anhui Polytechnic University, Wuhu, Anhui, China 241000 \\ zhzhgang526@163.com
}

\begin{abstract}
Keywords: expert system, knowledge representation, knowledge base, inference engine, engineering training
\end{abstract}

\begin{abstract}
Due to diversity of engineering training knowledge, complexity of its practitioners' needs, and low efficiency for an individual instructor to guide students, this paper proposes a new type of assisted teaching system based on expert system. It first elaborates the structure and significance of the system, then analyses knowledge representation which combines framework and productive representation. It also designs a corresponding knowledge base and specific examples are given. On this basis this paper proposes the specific reasoning process based on database and expounds the components of the system and its designing methods. In contemporary world, with the rapid growth of information age and artificial intelligence, the reform of higher education is inevitable. "1] "The Long-term education development Plan" (2010-2012) released by the Ministry of Education proposed new requirements for "informationization of the education". As an important part of higher education, engineering training undertakes a large amount of student internship annually. Due to differences in students' knowledge background, diverse practical problems occurred in internship, heavy workload and low efficiency for teachers' guidance, the use of expert system in engineering training might be possible to promote students' independent learning, broaden their horizon, and reduce teacher's burden. To this end, the author constructed a new kind of Teaching Assisted Expert System in Engineering Training (TAESET).
\end{abstract}

\section{Component of TAESET}

The structure of this system consists of six parts: man-machine interface, database, knowledge base, knowledge acquisition module, inference engine, and interpretation module.This system has multifaceted significances. (1) to cultivate Students' self-learning ability and broaden their knowledge; (2) to overcome the shortage of teaching hardware; (3) to improve the efficiency of teacher's counseling and reduce their burdens; (4) to provide a friendly and flexible interface, and guide those who are inexperienced in discovering and solving problems; (5) To provide a reference to the reform of engineering training, and serve as a useful example for informationization of the training center.

\section{Establishment and management of knowledge base}

(1) Knowledge acquisition. Knowledge acquisition refers to the process of acquiring knowledge from expert in specific field or other underlying sources (such as experts, books, databases, and people's experiences) by identifying, understanding, selecting, inducting and other steps, and then store and transmit knowledge in computers. ${ }^{[2]}$ Knowledge acquisition in engineering training is acquiring knowledge in different training types, and the acquisition process is in the sequence of description, observation, and acquisition. (a)Description: knowledge engineer interacts with a number of instructors, proposing the structured description of the training knowledge in this system. (b)Observation: without interrupting the instructor, knowledge engineer observes the measures and steps instructors taken to guide students. (c)Acquisition: acquire some crucial evaluation from the interaction between knowledge engineer and instructors, so that the knowledge 
engineer can carry out interactive search of needed training knowledge.

The process of knowledge acquisition in this system is passive. After knowledge engineer and engineering training experts' knowledge are systemized, a knowledge acquisition module should be built.

(2) Knowledge representation. In the field of engineering training, knowledge is usually empirical, causal, thus applies to productive representation. Framework is data structure that describes the object (a thing, an event, or a concept)'s properties. A framework is composed of several "slots", and each "slot" can be further divided into several "sides" based on the actual situation. A "slot" is used to describe a particular aspect of an object, and a "side" an aspect of the corresponding property. The properties of the "slot" and "side" are regarded as "slot value" and "side value" respectively. Whether framework, slot or side, all of them can attach some explanatory information, generally refers to a number of constraints.[3]

Table 1. Knowledge Representation in TAESET

\begin{tabular}{|c|c|c|c|}
\hline Frame & $\begin{array}{c}\text { Electrical Engineering } \\
\text { Practice } \\
\end{array}$ & \multicolumn{2}{|l|}{ Type 1} \\
\hline Slot1 & Inherited Slot & & \\
\hline Slot 2 & Common electrical Instrument & $\begin{array}{l}\text { Side 21: } \text { basic theory; } \\
\text { Side 22: } \text { usage }\end{array}$ & $\begin{array}{l}\text { Side } 211 ; \\
\text { Side } 221 ; \ldots . .\end{array}$ \\
\hline Slot 3 & $\begin{array}{l}\text { motor Jog } \\
\text { control,self-locking control }\end{array}$ & $\begin{array}{l}\text { Side 31: } \text { failure analysis; } \\
\text { Side 32: Schematic analysis; } \\
\text { Side 33: } \text { Special cases; } \\
\text { Side 34: }\end{array}$ & $\begin{array}{l}\text { Side } 311 ; \\
\text { Side } 321 ; \\
\text { Side } 331 ; \\
\text { Side } 341 ; \ldots \ldots\end{array}$ \\
\hline Slot 4 & $\begin{array}{l}\text { motor positive-negative } \\
\text { rotation }\end{array}$ & $\begin{array}{ll}\text { Side 41: } & \text { failure analysis; } \\
\text { Side 42: } & \text { schematic analysis; } \\
\text { Side 43: } & \text { special cases; } \\
\text { Side 44: } & \text { practical application }\end{array}$ & $\begin{array}{l}\text { Side 411; } \\
\text { Side 421; } \\
\text { Side 431; } \\
\text { Side 441; }\end{array}$ \\
\hline Slot 5 & household electrical system & $\begin{array}{l}\text { Side 51: failure analysis; } \\
\text { Side 52: schematic analysis; } \\
\text { Side 53: engineering } \\
\text { specifications; } \\
\text { Side 54: practical applications }\end{array}$ & $\begin{array}{l}\text { Side } 511 ; \\
\text { Side } 521 ; \\
\text { Side } 531 ; \\
\text { Side } 541 ; \ldots \ldots\end{array}$ \\
\hline
\end{tabular}

Note: Inherited Slot refers to common knowledge shared by different training types, including internship discipline, scoring criteria, equipment management and security issues.

Expert knowledge in teaching system is structurally hierarchical and modular, suitable for frame representation. In order to fully express the content and relationship of various internship activities, it is important to combine framework representation with productive representation. The former is for knowledge structure of various types, and the latter is for specific knowledge of different types.

With framework and productive representation, it may sum up and extract the knowledge of engineer training. Engineer training contains several types, and each type has several internship units, each unit has different knowledge module, and specific knowledge are presented under each module. The internship type is named as "framework", unit as "slot", knowledge module as "side", and each side contains specific knowledge. The knowledge contained in these "sides" are problems encountered in engineering training. This combined way of knowledge representation can be illustrated in Table 1.

(3)Establishment and maintenance of knowledge base. Knowledge base is a repository for storing domain knowledge, upon which the inference engine relies to work. The amount and quality of knowledge in the base determines the ability a system owns to solve problems. Generally speaking, the knowledge students needed can be divided into factual knowledge and reasoning knowledge. The former includes operating procedures, technology requirements, equipment management, tool usage, and application examples, aiming at students' retrieval of knowledge. The 
latter includes fault analysis, schematic exploration, special issue analysis, aiming at troubleshooting and problem solving.

According to different internship types and units, I designed the database tables that the system needed. Each of the following table represents a form in the database (Tables 2-5). In the database, knowledge is represented in tabular form, with a five-digit as ID code. For example, "No. 01411" refers to questions occurred in Frame 01 (Electrical Engineering Practice), Slot 4(motor positive-negative rotating slot), Side 412, which means "If contactor has no action, then check circuit control, power and fuse". This way of representation makes knowledge structurized and systemized, hence improved the efficiency of knowledge base.

Table 2:Frame module knowledge table in database

\begin{tabular}{|c|l|l|}
\hline Id & \multicolumn{1}{|c|}{ Frame } & \multicolumn{1}{c|}{ Slot } \\
\hline 01000 & Electrical internship & Correspond to Slot knowledge table 1 \\
\hline 02000 & Electronic internship & Correspond to Slot knowledge table 2 \\
\hline 03000 & Ordinary lathe internship & Correspond to Slot knowledge table 3 \\
\hline 04000 & Digital lathe internship & Correspond to Slot knowledge table 4 \\
\hline 05000 & Fitter internship & Correspond to Slot knowledge table 5 \\
\hline 06000 & Welder internship & Correspond to Slot knowledge table 6 \\
\hline
\end{tabular}

Table 3: Slot module knowledge in Electrical practice Framework

\begin{tabular}{|c|l|l|}
\hline Id & \multicolumn{1}{|c|}{ Slot } & \multicolumn{1}{c|}{ Side } \\
\hline 01100 & Inherited slot & Correspond to Side knowledge table 1 \\
\hline 01200 & Usage of electrical instruments & Correspond to Side knowledge table 2 \\
\hline 01300 & jog action/self-locking control & Correspond to Side knowledge table 3 \\
\hline 01400 & Motor positive/negative control & Correspond to Side knowledge table 4 \\
\hline 01500 & Household electrical system & Correspond to Side knowledge table 5 \\
\hline
\end{tabular}

Table 4: Motor positive-negative rotation control slot module side knowledge table

\begin{tabular}{|c|l|l|}
\hline Id & \multicolumn{1}{|c|}{ Side } & \multicolumn{1}{c|}{ Subside } \\
\hline 01410 & Failure analysis & Correspond to subside knowledge table 1 \\
\hline 01420 & Schematic analysis & Correspond to subside knowledge table 2 \\
\hline 01430 & Special cases & Correspond to subside knowledge table 3 \\
\hline 01440 & Practical application & Correspond to subside knowledge table 4 \\
\hline
\end{tabular}

Table 5: Failure analysis side/subside knowledge table

\begin{tabular}{|c|c|l|}
\hline Id & Subside & \multicolumn{1}{|c|}{ Knowledge } \\
\hline 01411 & Side 411 & IF motor cannot switch direction, Then change phase sequence. \\
\hline 01412 & Side 412 & $\begin{array}{l}\text { IF contactor has no action, Then check control circuit, power supply, and } \\
\text { fuse. }\end{array}$ \\
\hline 01412 & Side 413 & IF contactor does not self lock, Then check the self-locking contact. \\
\hline 01414 & Side 415 & $\begin{array}{l}\text { IF contactor does not interlock,Then check control circuit, and interlock } \\
\text { contact. }\end{array}$ \\
\hline
\end{tabular}

\section{Inference engine}

Inference is the process of simulating the thinking of artificial experts, and draw one conclusion from another. [4] The knowledge of engineering training can be divided into factual knowledge for students' self-learning and fault knowledge for their problem solving. These two kinds of knowledge are made in forms and stored in database. When needed, the system just carry on data searching; when new knowledge added, just update the corresponding database, thus greatly improve the system's efficiency. [5]

Given students' lack of experience and inaccuracy in describing problems and factual knowledge, with framework knowledge representation, the inference process is designed as step-by-step hints plus data search mode. Specific steps are as follows: (1) students choose different training types when prompted. (2) select internship unit module when prompted. (3) enter search information. (4) open the corresponding database; (5) find the cause and result, if the result is not found turn to step 
(7). (6) output related information; (7) if system does not work, request manual input of reasons and results, and reserve it in the repository. Then send the message to relevant users. if continue to search, turn to step (3), otherwise, stop.

\section{Acknowledgements}

1 This project was sponsored by Anhui Polytechnic University Youth Scientific Research Fund (2010YQ051).

\section{References}

[1] Cai Zixing, Xu Guangyou: Artificial Intelligence and its Application. Qinghua University Press, (2004).

[2] Wu Xindong: Expert System Design. Hefei: China Science and Technology University, (1990).

[3] Shen Yachen: Shu Zhongmei. Cases and Knowledge Database Studies based on Framework and Productive Representation. Southern Medical University Journal, Vol. 26(2006), p.1467-1468.

[4] P.H. Winston: Artificial Intelligence. Beijing: Science Press, (2000).

[5] Wang Xiaojun, Zhou Changsheng: A Knowledge Representation and Inference Method Based on Relative Database, Control Engineering,Vol. 12(2005), p.41-43. 